SN navigation surgery has been commonly performed in breast cancer surgery to reduce the extent of lymphadenectomy, leading to a reduction in operative complications. On the other hand, lymphadenectomy has not been found to increase the operative mortality or complications relative to lymph node sampling in NSCLC surgery. ${ }^{2}$

SN identification has a new significance in recent NSCLC surgery. With the increased incidence of detection of small-sized NSCLC, a phase III randomized trial of lobectomy versus segmentectomy for small-sized peripheral NSCLC is ongoing. ${ }^{3}$ The eligibility criteria for segmentectomy state that there should be "no lymph node metastasis" and that patients with node-positive cases should undergo lobectomy with standard lymphadenectomy to ensure radical resection. Because the accuracy of clinical nodal staging even with fludeoxyglucose F18 positron emission tomography and computed tomography is still low, ${ }^{4}$ intraoperative sampling and frozen sectioning of lymph nodes are indispensable for segmentectomy. Random sampling of N1 lymph nodes has no meaning, however, because the lymphatic flow of the lung varies. Therefore, SN identification is important for patients with clinical stage I NSCLC who are candidates for segmentectomy. ${ }^{5}$ Recently, an endoscopic ICG-NIF imaging system became commercially available, and this system can be used during VATS.

In conclusion, this report shows the utility of an endoscopic ICG-NIF imaging system for SN identification during VATS, with especial value in identifying subpleural lymphatic spread.

\section{References}

1. Riquet M, Assouad J, Bagan P, Foucault C, Le Pimpec Barthes F, Dujon A, et al. Skip mediastinal lymph node metastasis and lung cancer: a particular N2 subgroup with a better prognosis. Ann Thorac Surg. 2005;79:225-33.

2. Allen MS, Darling GE, Pechet TT, Mitchell JD, Herndon JE II, Landreneau RJ, et al., ACOSOG Z0030 Study Group. Morbidity and mortality of major pulmonary resections in patients with early-stage lung cancer: initial results of the randomized, prospective ACOSOG Z0030 trial. Ann Thorac Surg. 2006;81:1013-9; discussion 1019-20.

3. Nakamura K, Saji H, Nakajima R, Okada M, Asamura H, Shibata T, et al. A phase III randomized trial of lobectomy versus limited resection for small-sized peripheral nonsmall cell lung cancer (JCOG0802/WJOG4607L). Jpn J Clin Oncol. 2010;40:271-4.

4. Gómez-Caro A, Garcia S, Reguart N, Arguis P, Sanchez M, Gimferrer JM, et al. Incidence of occult mediastinal node involvement in cN0 non-small-cell lung cancer patients after negative uptake of positron emission tomography/computer tomography scan. Eur J Cardiothorac Surg. 2010;37:1168-74.

5. Takizawa H, Kondo K, Toba H, Kajiura K, Ali AH, Sakiyama S, et al. Computed tomography lymphography by transbronchial injection of iopamidol to identify sentinel nodes in preoperative patients with non-small cell lung cancer: a pilot study. J Thorac Cardiovasc Surg. 2012;144:94-9.

\title{
Minimally invasive enucleation of a large, extensively calcified esophageal leiomyoma
}

Ryan A. Macke, MD, ${ }^{\mathrm{a}}$ James D. Luketich, MD, ${ }^{\mathrm{b}}$ Katie S. Nason, MD, ${ }^{\mathrm{b}}$ and Matthew J. Schuchert, MD, ${ }^{\mathrm{b}}$ Madison, Wis, and Pittsburgh, Pa

Video clip is available online.

A number of gastrointestinal tumors may present with macroscopic calcifications; however, true esophageal

\footnotetext{
From the Division of Cardiothoracic Surgery, ${ }^{\text {a }}$ Department of Surgery, University of Wisconsin Hospitals and Clinics, School of Medicine and Public Health, Madison, Wis; and the Division of Thoracic and Foregut Surgery, ${ }^{\mathrm{b}}$ Department of Cardiothoracic Surgery, University of Pittsburgh Medical Center, Pittsburgh, Pa.

Disclosures: Authors have nothing to disclose with regard to commercial support.

Received for publication Oct 23, 2013; revisions received Dec 11, 2013; accepted for publication Dec 17, 2013; available ahead of print Feb 9, 2014.

Address for reprints: Ryan A. Macke, MD, Division of Cardiothoracic Surgery, Department of Surgery, University of Wisconsin Hospitals and Clinics/School of Medicine and Public Health, H4 318/CSC 600 Highland Ave, Madison, WI 53792-3236 (E-mail: macke@surgery.wisc.edu).

J Thorac Cardiovasc Surg 2014;147:e52-4

$0022-5223 / \$ 36.00$

Copyright (c) 2014 by The American Association for Thoracic Surgery

http://dx.doi.org/10.1016/j.jtcvs.2013.12.054
}

tumors with this characteristic are uncommon. Leiomyomas are the most likely esophageal neoplasms to develop calcifications, and the presence of calcification within an esophageal tumor strongly suggests this diagnosis. We present a case of a rare calcified, distal esophageal leiomyoma that was successfully enucleated through a thoracoscopic approach.

\section{CLINICAL SUMMARY}

A 63-year-old man was referred to our institution with reports of vague left-sided chest pain for the previous 3 months and new-onset atrial fibrillation. A chest radiograph suggested a calcified posterior mediastinal mass (Figure 1, A). Workup continued with a barium esophagogram, which demonstrated a large, smooth-bordered, extraluminal, partially-obstructing distal esophageal mass (Figure 1, B). A subsequent computed tomographic scan of the chest confirmed the intramural, multilobulated, calcified mass measuring $7 \mathrm{~cm}$ in maximum diameter 

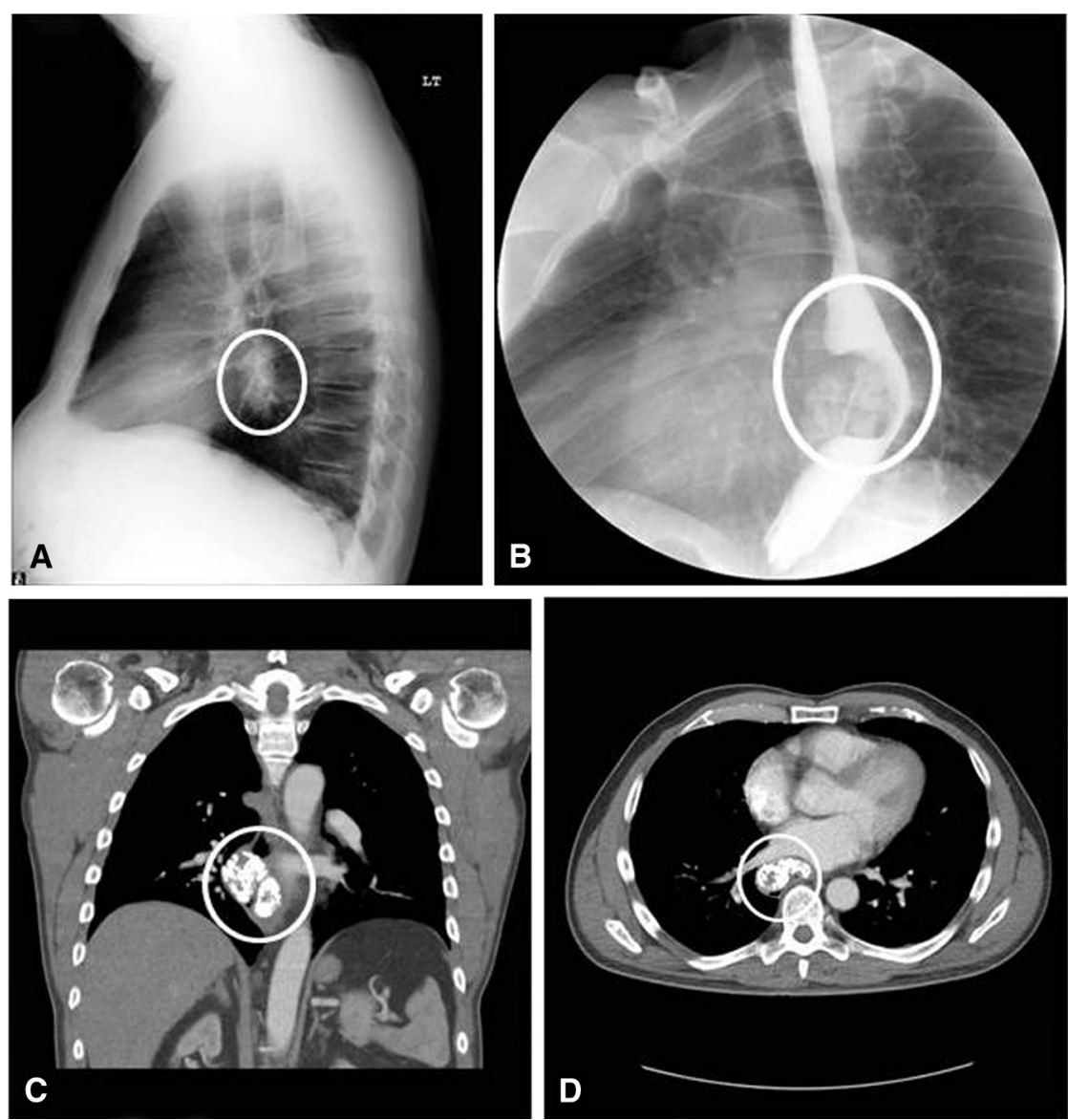

FIGURE 1. A, Lateral chest radiograph. B, Barium esophagogram. C, Computed tomographic coronal image. D, Computed tomographic axial image.

(Figure 1, C and D). To characterize the mass further, esophagoduodenoscopy and endoscopic ultrasonography were performed, demonstrating the submucosal mass extending from 32 to $37 \mathrm{~cm}$ from the incisors and encompassing half the luminal circumference. The mass had heterogeneous echogenicity with borders that were difficult to distinguish because of the extensive calcifications. Because of the anticipated enucleation of the tumor, no biopsies were performed.

In light of the patient's symptoms and suspicion that his newly diagnosed arrhythmia might be due to mass effect of the tumor on the left atrium, surgical resection was recommended. The patient gave consent to enucleation of the esophageal mass by a minimally invasive thoracoscopic approach, with the possibility of converting to a minimally invasive esophagectomy should the lesion appear malignant. The minimally invasive approach used was similar to the technique previously reported by our group for resection of benign esophageal tumors. ${ }^{1}$ After standard port placement, limited esophageal mobilization was carried out with ultrasonic shears, with care taken to preserve the right vagus nerve and its branches. A longitudinal myotomy was made overlying the mass. The lesion was then enucleated with endoscopic scissors with electrocautery and blunt dissection. Although the tumor was somewhat adherent to the surrounding layers of the esophagus, there were no signs of invasion into the mucosa or overlying muscularis propria. Some difficulty was encountered in manipulating the mass because of the extensive calcifications, precluding our usual technique of placing a stitch in the mass for manipulation. A single port incision was then enlarged to approximately $3 \mathrm{~cm}$, and the mass was removed (Figure 2, $A$ and $B$ ). Although the muscularis propria was somewhat attenuated, it was considered to be thick enough to be closed over the mucosa in an effort to prevent future diverticular formation. The myotomy was closed with interrupted sutures, and a single chest tube was placed.

Final pathologic examination demonstrated the lesion to be composed of cytologically bland spindle cells arranged in intersecting fascicles with extensive calcifications scattered throughout. No mitoses, necrosis, or other signs of malignancy were present. Immunohistochemical stains were performed, with the spindle cells staining positive for antimitochondrial antibody and desmin. Results for discovered on GIST-1 protein, CD34, and c-kit were 

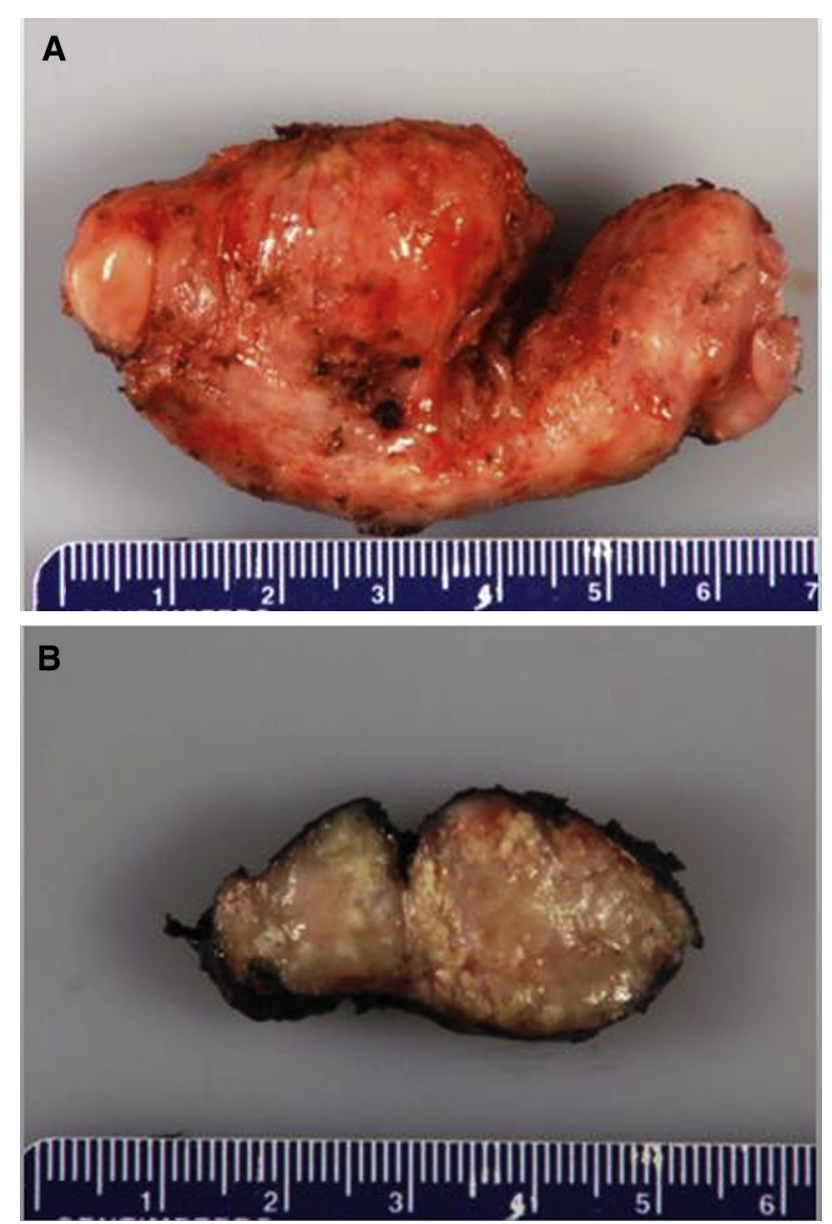

FIGURE 2. A, Gross specimen demonstrating multiple lobulations. $\mathrm{B}$, Sectioned specimen demonstrating calcifications.

negative. These findings confirmed our suspicion that the lesion was a calcified leiomyoma.

A water-soluble contrast esophagogram performed on postoperative day 1 did not demonstrate any radiographic evidence of a leak, and contrast passed freely into the stomach. The patient's diet was then advanced, and he was discharged to home on postoperative day 3 tolerating a full liquid diet. After resection the patient's chest, the pain resolved, and no further arrhythmias were noted during the immediate postoperative period or on short-term follow-up with the assistance of $\beta$-blockade.

\section{DISCUSSION}

Unlike tumors found in other locations of the gastrointestinal tract, identification of an esophageal tumor with calcifications is an extremely rare finding. ${ }^{2}$ Only 2 reports of calcified malignant esophageal lesions have been published in the literature: the first was a leiomyosarcoma, and the other was an extraosseous osteosarcoma. ${ }^{3,4}$ There are no reports of this characteristic being present in the vastly more common esophageal carcinomas. Nor have there been reports of calcified benign tumors of the esophagus, with the exception of leiomyomas. Seremetis and colleagues ${ }^{5}$ reported data on 838 cases of esophageal leiomyomas, identifying calcifications within $1.8 \%$ of tumors. Because this characteristic appears to be unique to esophageal leiomyomas, some authors have suggested that the presence of calcifications within a true esophageal tumor may be diagnostic for this lesion. ${ }^{2,3}$ In light of the tendency to avoid biopsy of suspected leiomyomas because of the potential for increased difficulty enucleating these tumors, identification of calcifications within an esophageal tumor could prove to be useful information to reassure the clinician that it is indeed a benign lesion.

\section{References}

1. Kent M, d'Amato T, Nordman C, Schuchert M, Landreneau R, Alvelo-Rivera M, et al. Minimally invasive resection of benign esophageal tumors. J Thorac Cardiovasc Surg. 2007;134:176-81.

2. Ghahremani GG, Meyers MA, Port RB. Calcified primary tumors of the gastrointestinal tract. Gastrointest Radiol. 1978;2:331-9.

3. Itai Y, Simazu H. Leiomyosarcoma of the oesophagus with dense calcifications. Br J Radiol. 1978;51:469-71.

4. Wegner RE, McGrath KM, Luketich JD, Friedland DM. Extraosseous osteosarcoma of the esophagus: a case report. Sarcoma. 2010;2010:907127.

5. Seremetis MG, Lyons WS, deGuzman VC, Peabody JW Jr. Leiomyomata of the esophagus: an analysis of 838 cases. Cancer. 1976;39:2166-77. 